\title{
Interfacial Fracture Toughness Measurement of Welded Babbitt alloy SnSb11Cu6/20Steel
}

\author{
Yuepeng $\mathrm{Gao}^{1}$, Janmei Wang ${ }^{1}$, and Yuyang Liu ${ }^{1}$ \\ ${ }^{1}$ Taiyuan University of Science and Technology
}

March 3, 2021

\begin{abstract}
The interface fracture toughness of $\mathrm{SnSb} 11 \mathrm{Cu} 6 / 20$ steel was measured by calculating the critical energy release rate and stress phase angle of the interface crack. A three-point bending test was used to introduce cracks into the bonding interface, and the cohesion model of the bonding interface was established through experimental data. Through finite element analysis of load-deflection curves with and without interface crack propagation, the crack initiation point is found. Then the energy calculation model of crack propagation is established, and the critical energy release rate is obtained using the virtual crack growth criterion. The calculation results of the stress phase angle show that the crack propagation is greatly affected by the normal stress after the babbitt alloy layer fractures. If the strength of the substrate material is weaker, the crack will continue to expand in the tangent perpendicular to the crack tip.
\end{abstract}

\section{Hosted file}

Revised manuscript.pdf available at https://authorea.com/users/373419/articles/511809interfacial-fracture-toughness-measurement-of-welded-babbitt-alloy-snsb11cu6-20steel

\section{Hosted file}

Table1.pdf available at https://authorea.com/users/373419/articles/511809-interfacialfracture-toughness-measurement-of-welded-babbitt-alloy-snsb11cu6-20steel

\section{Hosted file}

Table2.pdf available at https://authorea.com/users/373419/articles/511809-interfacialfracture-toughness-measurement-of-welded-babbitt-alloy-snsb11cu6-20steel

\section{Hosted file}

Table3.pdf available at https://authorea.com/users/373419/articles/511809-interfacialfracture-toughness-measurement-of-welded-babbitt-alloy-snsb11cu6-20steel

\section{Hosted file}

Table4.pdf available at https://authorea.com/users/373419/articles/511809-interfacialfracture-toughness-measurement-of-welded-babbitt-alloy-snsb11cu6-20steel 

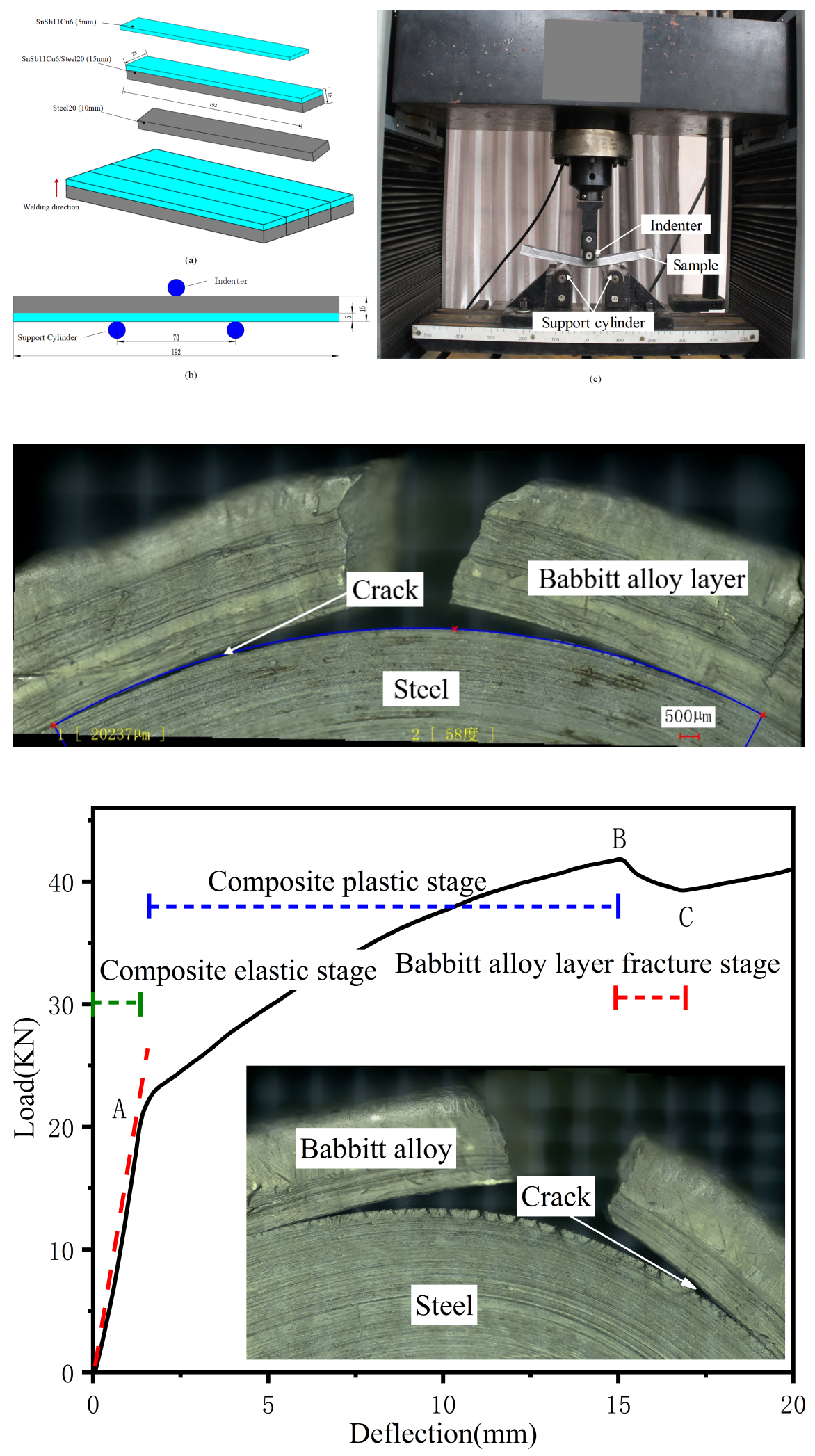

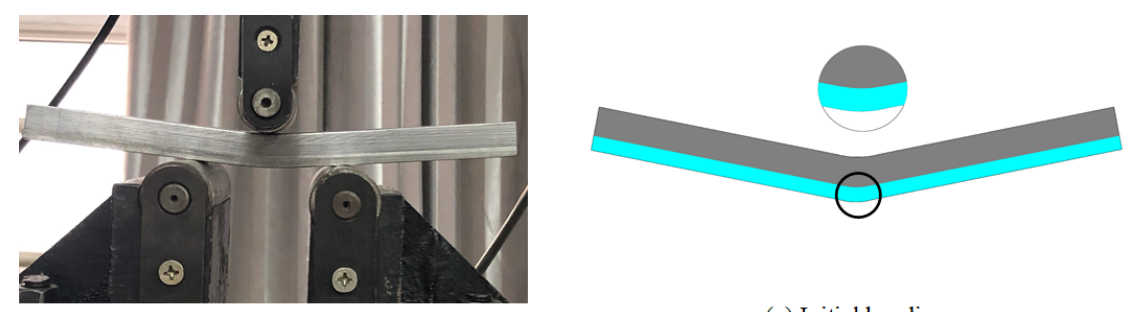

(a) Initial bending
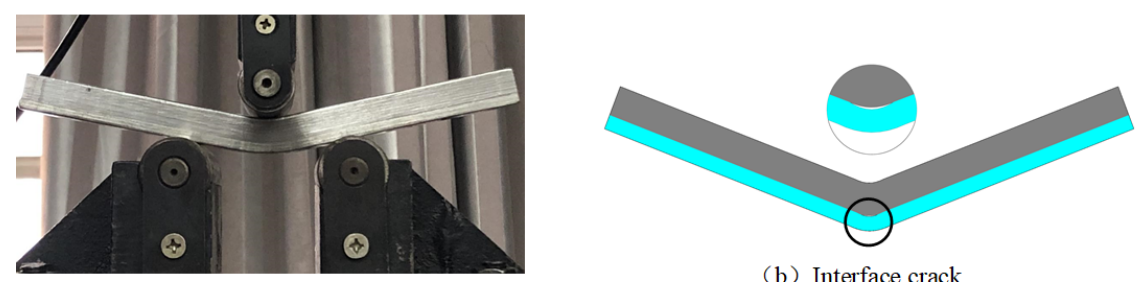

(b) Interface crack
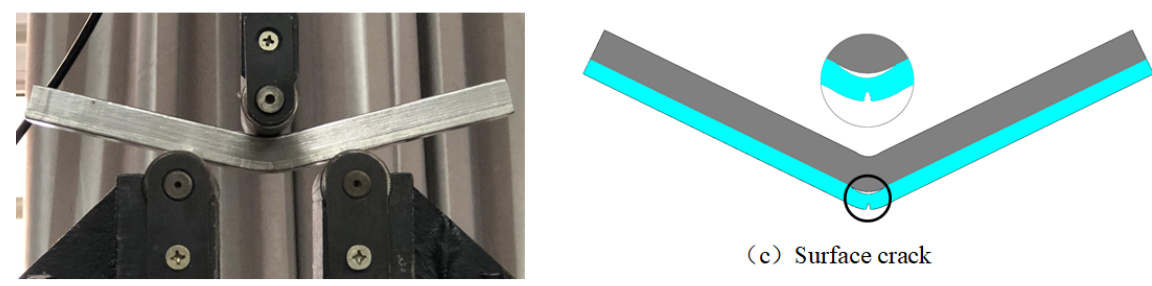

(c) Surface crack
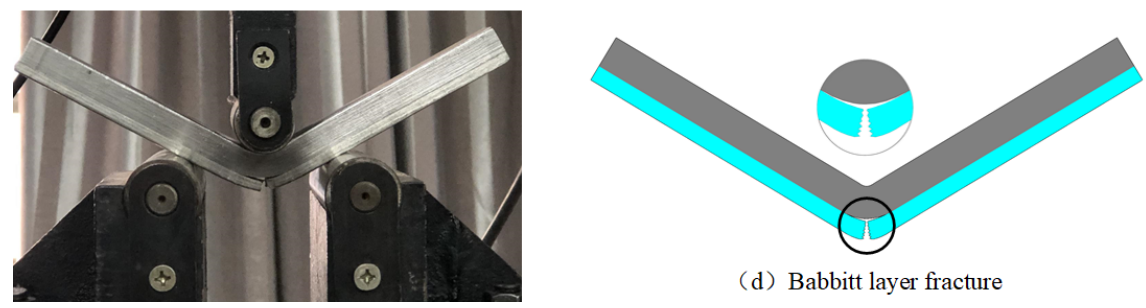

(d) Babbitt layer fracture

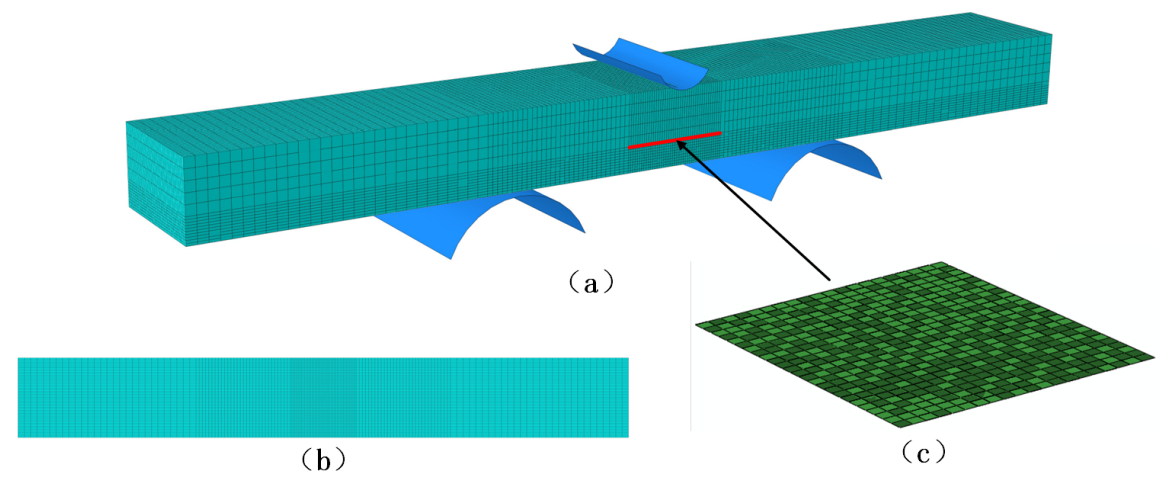



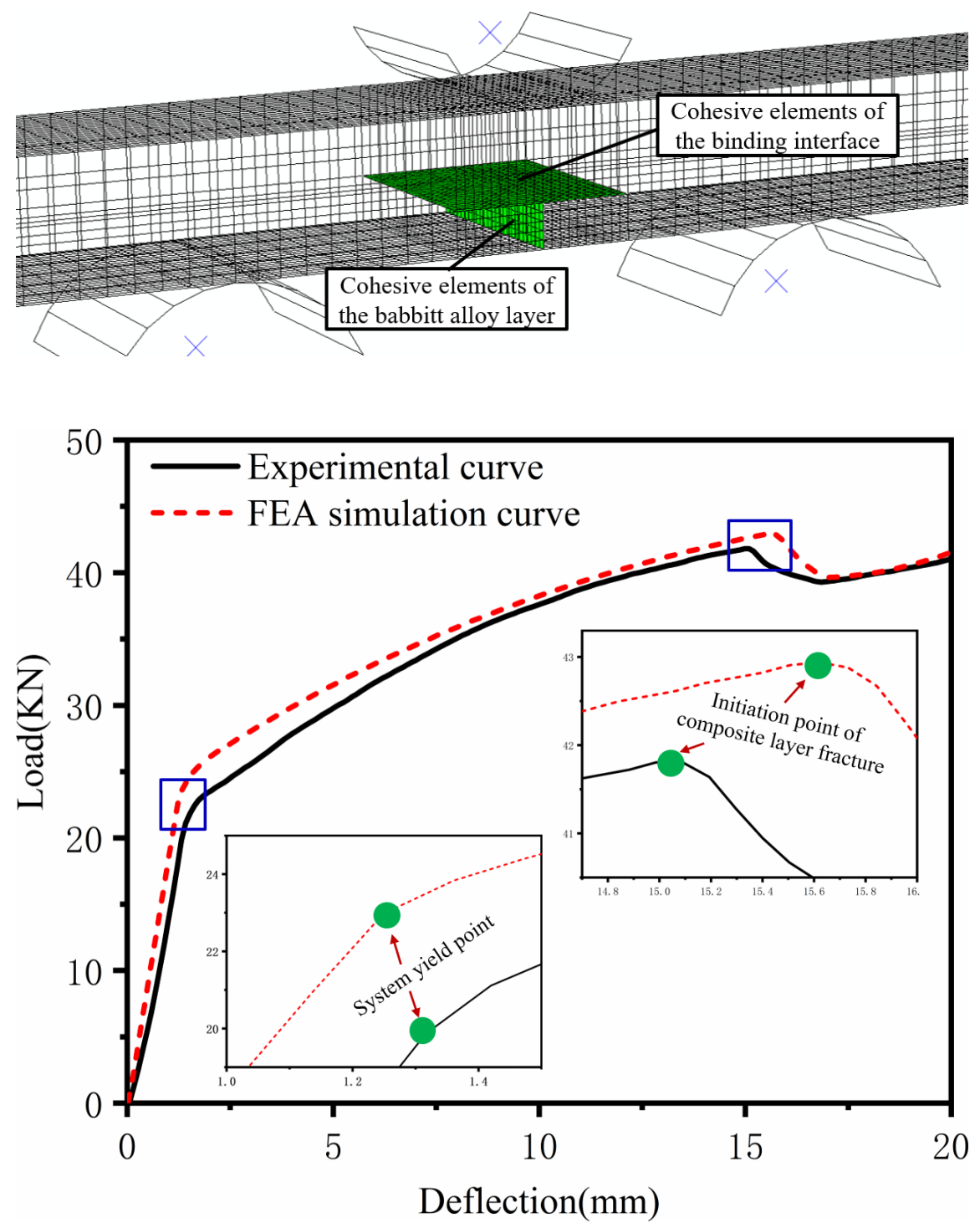

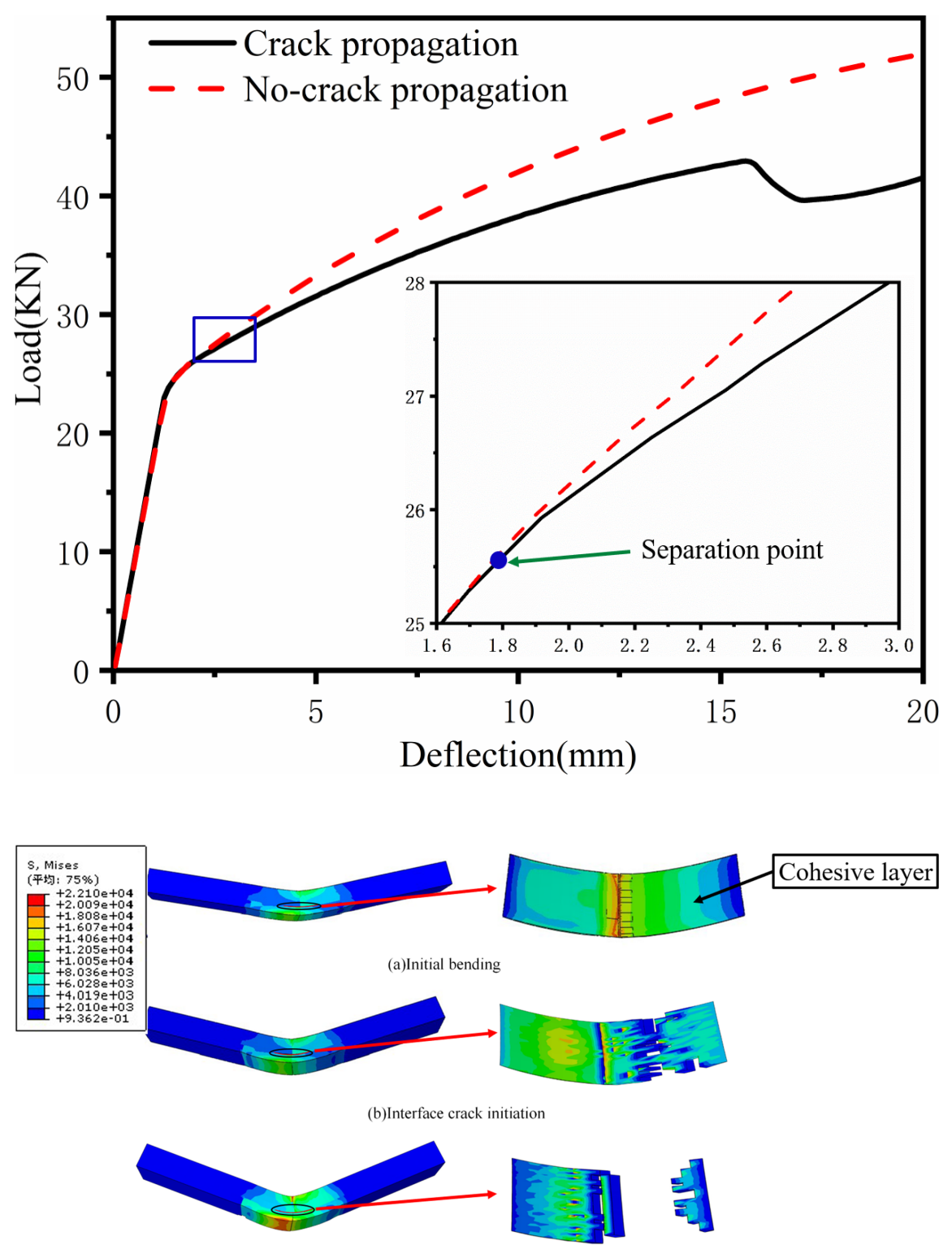

(c)Interface crack propagation and surface crack initiation in babbitt alloy
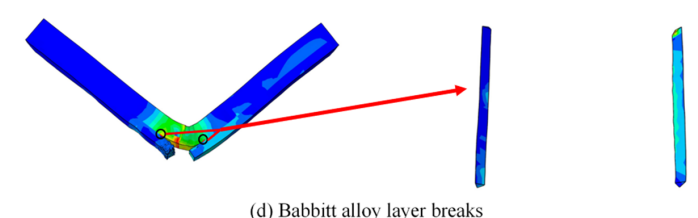

Babbitt alloy layer break 


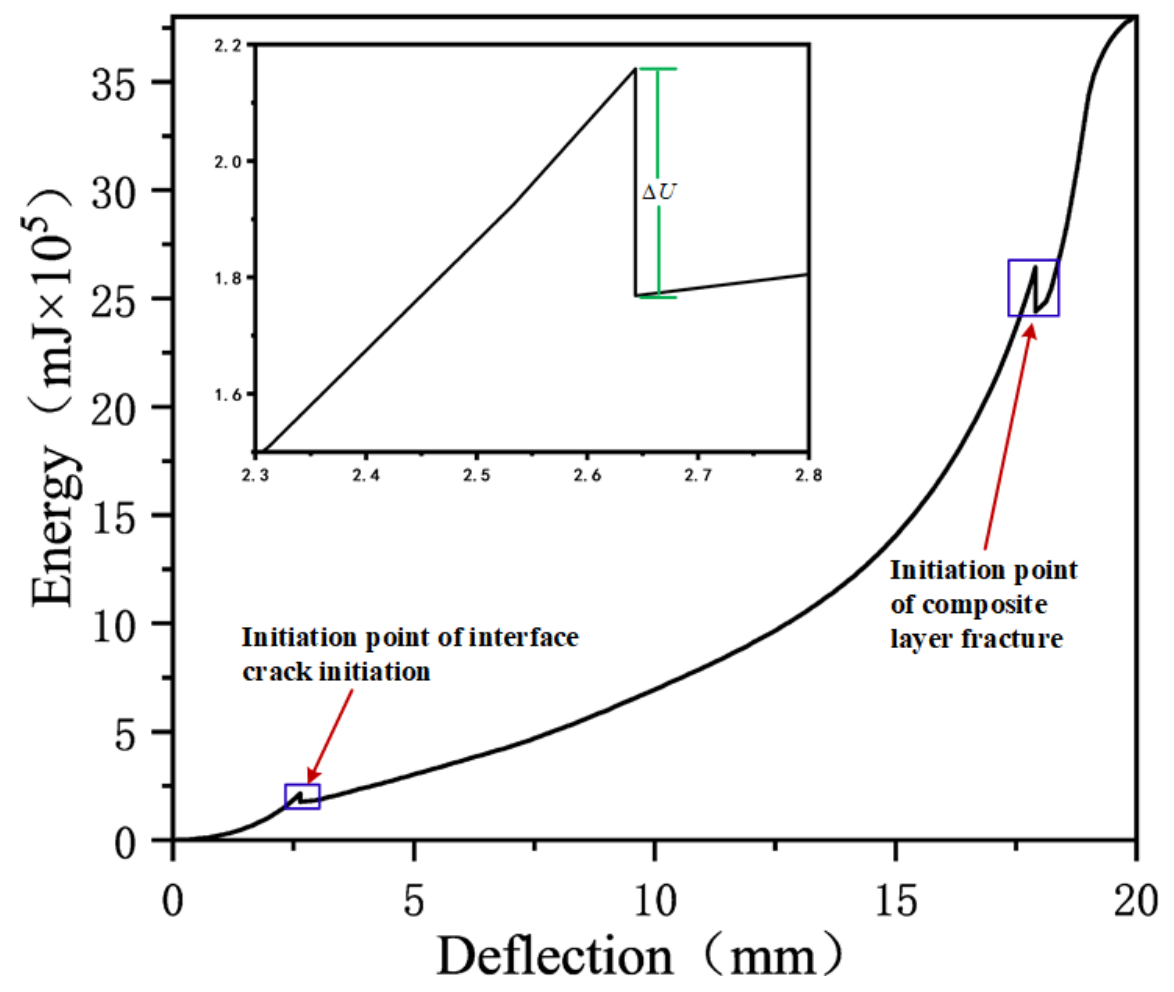

